Labovitz School of Business \& Economics, University of Minnesota Duluth, 11 E. Superior Street, Suite 210, Duluth, MN 55802

\title{
Temporal Sequence Effects: a Memory Framework
}

Nicole Votolato Montgomery, The Ohio State University

H. Rao Unnava, The Ohio State University

While much attention has been given recently to studying temporal sequences of events, virtually no attention has been given to the underlying mechanism responsible for how people form global retrospective evaluations of temporal sequences. The findings from this research suggest that a memory-based framework can provide a parsimonious, comprehensive explanation for retrospective evaluations. In addition to accounting for past findings such as a preference for improving over declining temporal sequences and the important role of peak (both high intensity and unique) experiences, we demonstrate that imposing a delay prior to retrospective evaluations can create a preference reversal due to the reduced accessibility of final or common instances.

[to cite]:

Nicole Votolato Montgomery and H. Rao Unnava (2007), "Temporal Sequence Effects: a Memory Framework", in NA Advances in Consumer Research Volume 34, eds. Gavan Fitzsimons and Vicki Morwitz, Duluth, MN : Association for Consumer Research, Pages: 743-744.

[url]:

http://www.acrwebsite.org/volumes/12602/volumes/v34/NA-34

\section{[copyright notice]:}

This work is copyrighted by The Association for Consumer Research. For permission to copy or use this work in whole or in part, please contact the Copyright Clearance Center at http://www.copyright.com/. 


\title{
Temporal Sequence Effects: A Memory Framework
}

\author{
Nicole Votolato Montgomery, Ohio State University, USA
}

H. Rao Unnava, Ohio State University, USA

\section{EXTENDED ABSTRACT}

While much attention has been given recently to studying temporal sequences of events, few have offered explanations to account for how people integrate these events into a holistic evaluation of the experience, and virtually no attention has been given to the underlying mechanism involved. A temporal sequence refers to an experience that consists of a series of outcomes spaced over time. The findings from the temporal sequence literature indicate that people form global retrospective ratings of an experience using salient characteristics of the experience, such as the peak intensity, the end intensity, and the trend (Ariely, Kahneman, and Loewenstein 2000). The current explanations that have been proposed to account for temporal sequence findings (e.g., Ariely and Carmon 2000; Baumgartner, Sujan, and Padgett 1997) tend to be ad hoc in nature and are limited to explaining reported findings rather than offering a comprehensive account of the findings in the literature. We propose that adopting a memory-based framework can provide a parsimonious explanation for the findings on retrospective evaluations of temporal sequence.

Retrospective evaluations inherently require that people recall aspects of the experience. Past research suggests that information that is easily accessible in memory will impact judgments the most (e.g., Hamilton and Gifford 1976; Tversky and Kahneman 1973). Accessibility of information has been studied in the memory literature using a free recall task in which people are presented with a list of words that they may recall in any order (Ashcraft 2002). Findings from this research show that respondents have higher recall performance on early items on a list (primacy) because these items receive sufficient rehearsals to transfer them to long-term memory and final items on a list (recency) because these items are temporarily available in short-term memory. Though a temporal sequence is affective in nature and a free recall task is cognitive in nature, we suggest that there are parallels between an affective experience and the experience of learning a list. Thus, memory findings on free recall are expected to explain current findings in the temporal sequence literature and predict findings that would otherwise not be predicted by the temporal sequence literature.

In studies 1 and 2, we test whether a memory-based framework, utilizing primacy and recency effects, can account for the impact of the beginning, end, and trend of an experience on retrospective evaluations of the experience (e.g., Ariely 1998; Redelmeier and Kahneman 1996). Specifically, we argue that assuming that a memory-based structure is responsible for temporal sequence findings, then introducing a delay between an affective experience and evaluations of the experience should diminish the impact of the end of an experience and enhance the impact of the beginning of an experience on retrospective evaluations, reversing consumer preferences for improving versus declining trends. Consistent with expectations, in study 1 we show that an improving vacation experience is evaluated more favorably immediately than after a delay. Consistent with primacy and recency effects, recall of the early instances was not affected by the delay; however, recall of the final incidents declined following a delay. Study 2 replicates the findings from study 1 using both an improving and declining vacation trend and demonstrates that the differential memory for events is based on their temporal location, not their valence. Consistent with a memory-based explanation, the final events in the vacation are heavily weighted when the experience is evaluated immediately, replicating the findings from Redelmeier and Kahneman (1996). However, the initial events are heavily weighted when the experience is evaluated following a delay, resulting in higher evaluations for the improving trend immediately but a preference for the declining trend following a delay, a finding which is predicted by proposed framework but contrary to previous findings in the temporal sequence literature (e.g., Ariely 1998; Redelmeier and Kahneman 1996).

Studies 3 and 4 further confirm the role of memory by manipulating the uniqueness of one event in a vacation experience to test whether a memory-based structure can account for the impact of the peak of an experience on retrospective evaluations of the experience (e.g., Kahneman et al. 1993). Uniqueness is examined because past research using diary studies suggests that intense emotional experiences are unique (Bower 1981), leading to the expectation that peak intensity incidents are more accessible than other incidents because they are uncommon, consistent with the von Restorff effect in memory (Wallace 1965). We argue that if a peak intensity event occurs in a temporal location of an experience that impedes memory, such as the center or end of an experience that is evaluated following a delay (Ashcraft 2002), then making that event unique will facilitate recall of the event and result in that event being heavily weighted in retrospective evaluations of the experience. Consistent with expectations, study 3 shows that making the peak intensity final event in an improving vacation experience atypical enhances the recall of this event following a delay relative to a common event with the same affective intensity, demonstrating a recovery of the recency effect previously shown to diminish after a delay. Additionally, study 3 shows that evaluations are based on the peak intensity final event when the event is unique, consistent with Kahneman et al. (1993), while evaluations are based on the initial events when the peak intensity final event is common, contrary to previous findings (e.g., Fredrickson and Kahneman 1993). Study 4 further confirms these findings by replicating the results with the peak incident in the center of an experience and by demonstrating the robustness of the effects for both positively and negatively-valenced peak incidents.

In sum, the findings from this research demonstrate that a conventional memory-based framework appears to provide a coherent structure to account for consumers' use of specific aspects of a temporal sequence when forming retrospective evaluations of an experience. In addition to accounting for past findings such as a preference for improving over declining temporal sequences and the important role of peak (both high intensity and unique) experiences, our findings demonstrate that imposing a delay prior to retrospective evaluations can create a preference reversal due to the reduced accessibility of final or common instances.

\section{REFERENCES}

Ariely, Dan (1998), "Combining Experiences Over Time: The Effects of Duration, Intensity Changes, and On-line Measurements on Retrospective Pain Evaluations," Journal of Behavioral Decision Making, 11 (March), 19-45.

Ariely, Dan and Ziv Carmon (2000), "Gestalt Characteristics of Experiences: The Defining Features of Summarized Events," Journal of Behavioral Decision Making, 13 (April/June), 191-201. 
Ariely, Dan, Daniel Kahneman, and George F. Loewenstein (2000), "Joint Comment on 'When Does Duration Matter in Judgment and Decision Making?"' Journal of Experimental Psychology: General, 129 (December), 524-29.

Ashcraft, Mark H. (2002), Cognition, Upper Saddle River, NJ: Prentice Hall.

Baumgartner, Hans, Mita Sujan, and Dan Padgett (1997), "Patterns of Affective Reactions to Advertisements: The Integration of Moment-to-Moment Responses into Overall Judgments," Journal of Marketing Research, 34 (May), 21932.

Bower, Gordon H. (1981), "Mood and Memory," American Psychologist, 36 (February), 129-48.

Fredrickson, Barbara L. and Daniel Kahneman (1993), "Duration Neglect in Retrospective Evaluations of Affective Episodes," Journal of Personality and Social Psychology, 65 (July), 44-55.

Hamilton, D.L. and Gifford, R.K. (1976), "Illusionary Correlation in Interpersonal Perception: A Cognitive Basis of Stereotypic Judgments," Journal of Experimental Social Psychology, 12 (July), 392-407.

Kahneman, Daniel, Barbara L. Fredrickson, Charles A. Schreiber, and Donald A. Redelmeier (1993), "When More Pain is Preferred to Less: Adding a Better End," Psychological Science, 4 (6), 401-05.

Redelmeier, Donald A. and Daniel Kahneman (1996), "Patients' Memories of Painful Medical Treatments: Real-Time and Retrospective Evaluations of Two Minimally Invasive Procedures," Pain, 66 (1), 3-8.

Tversky, Amos and Daniel Kahneman (1973), "Availability: A Heuristic for Judging Frequency and Probability," Cognitive Psychology, 5 (September), 207-32.

Wallace, W. (1965), "Review of the Historical, Empirical, and Theoretical Status of the von Restorff Phenomenon," Psychological Bulletin, 63 (6), 410-24. 